\title{
ECOLOGICAL AND PHYSIOLOGICAL OBSERVATIONS ON POLYMORPHIC POPULATIONS OF THE TOAD BUFO ARENARUM HENSEL, FROM ARGENTINE
}

J. M. CEI

Instituto de Biologia, Universidad Nacional de Cuyo, Mendoza, Argentine, and Centro de Investigaciones Zoologicas, Universidad de Chile, Santiago de Chile

The distribution area of Bufo arenarum Hensel extends from southern Brazil southward to southern Patagonia. This toad species appears to be an ecologically very versatile form, since it occurs in a great variety of ecological niches available in its distribution regions, except for the high Cordilleras. Despite the absence of obvious natural barriers between the different populations, the latter often differ in a variety of characters, such as colors and patterns, certain reflexes, and metabolic rates. These differences seem to be correlated with environmental conditions. Particularly interesting are the differences observed between the populations of the arid deserts near Mendoza and those of San Luiz, Cordoba, and Tucuman. The following account may be regarded as an exploratory study which is needed for a more thorough analysis of the population structure of the species.

\section{Materials and Methods}

The specimens were collected in the following regions: (1) Mendoza (646 specimens of both sexes), Parque San Martin, Lujan-Maipu $20 \mathrm{kms}$ eastward, Las Heras $10 \mathrm{kms}$ westward; all these collecting sites are at elevations $700-800$ $\mathbf{m}$, in artificial ponds and pools. (2) San Luiz (70 specimens), El Volcan, elevation $900-1000 \mathrm{~m}$, in little streams among hills. (3) Cordoba (38 specimens), Rio Cuarto, Rio Ajis, Alta Gracia, mostly breeding toads. (4) Tucuman (401 specimens), near the town of San Miguel, elevation 400-500 m, Rio Sali, some breeding specimens collected. (5) Buenos Aires (55 specimens), Avellaneda, near the town, not breeding individuals. Finally, some comparative data can be reported on the populations of $B u f o$ spinulosus Wiegmann, a relative of $B$. arenarum living in Chile.

Cei (1956) has reported that some individuals in certain populations of $B$. arenarum exhibit the so-called hypnotic reflex, while other individuals do not. This behavioral trait may be seen in the photographs in plate 1 . The reflex is easily provoked by a moderate pressure on the throat. The period of cataleptic inhibition is variable from individual to individual; it may last for 15 minutes and even longer. Life in captivity does not alter the reflex in those individuals who have it. The reflex may also be provoked in individuals suddenly plunged in water or pinched. It exists equally in breeding and in non-breeding individuals.

The characters of pigmentation have been scored in living specimens. Measurements on the metabolic rates (oxygen consumption) were made in glass chambers, with the classical volumetric technique. Water regulation was studied measuring the percentage of weight loss, during a controlled time, in standard glass chambers with $\mathrm{CaCl}_{2}$ at temperatures between $23^{\circ}$ and $26^{\circ} \mathrm{C}$. Data on resistance of different populations to climatic changes were obtained using terraria of standard construction and capacity, the animals being kept under identical 


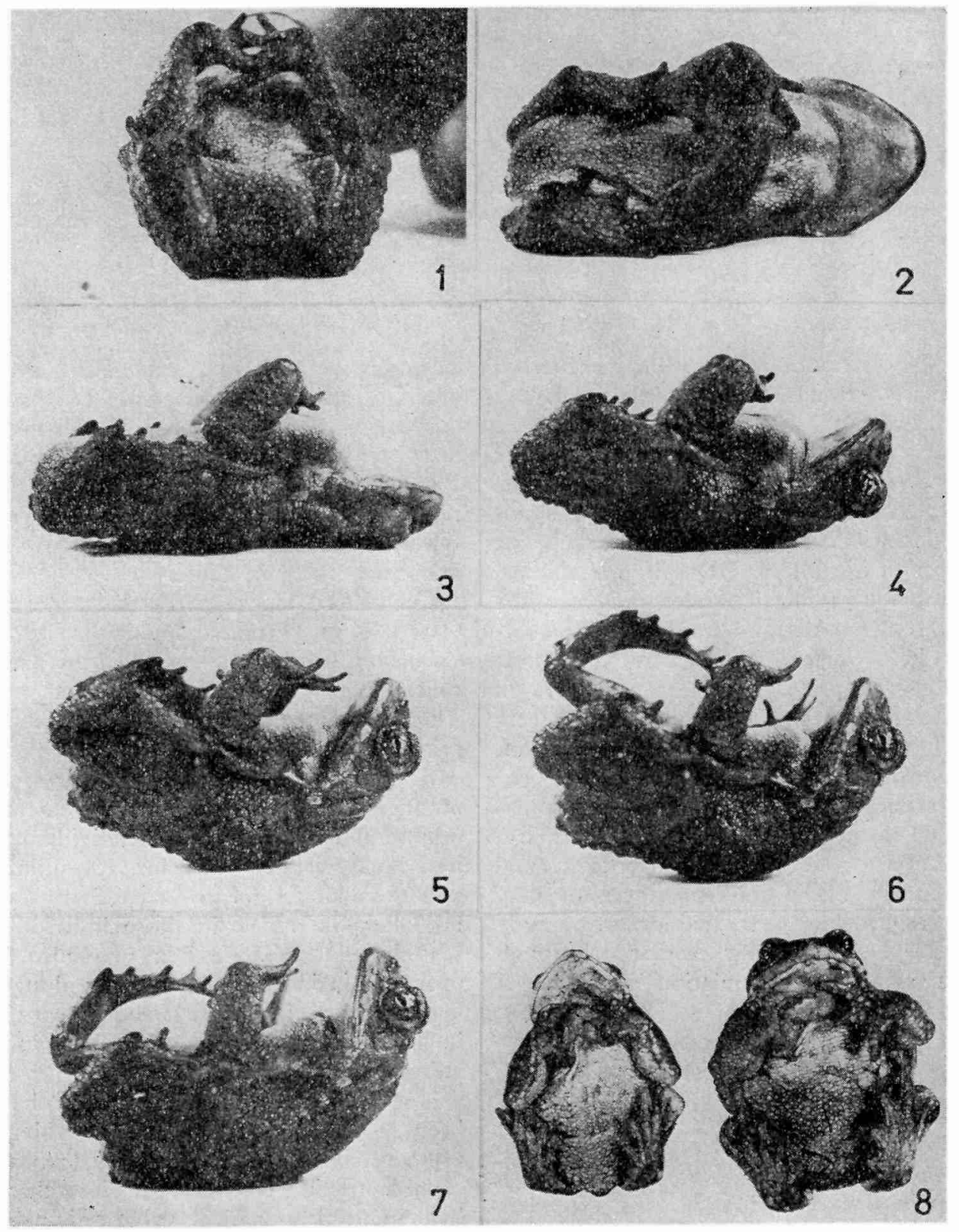

PLATE 1. The hypnotic reflex in the Mendoza, Argentine, population of Bufo arenarum. Nos. 1-3, manifestation of the reflex; Nos. 4-7, progressive loss of the inhibition. No. 8, the same reflex in a male of Bufo spinulosus from the population of Vallenar, Chile.

environmental conditions. All the observations on ecological resistance, water loss, and metabolic rates were made at Santiago de Chile, in the laboratory of the C. I. Z. (Centro Investigaciones Zoologicas de la Universidad de Chile) between December of 1956 and November of 1957.

The Observations

The data on the coloration and on the hypnotic reflex are summarized in table 
TABLE 1. Frequencies of spotted and unspotted individuals, and of those showing and not showing the hypnotic reflex in different populations

\begin{tabular}{|c|c|c|c|c|}
\hline Localities & $\begin{array}{l}\text { No yeilow spots } \\
\text { Reflex present }\end{array}$ & $\begin{array}{l}\text { No yellow spots } \\
\text { Reflex absent }\end{array}$ & $\begin{array}{l}\text { Yellow spots } \\
\text { Reflex present }\end{array}$ & $\begin{array}{l}\text { Yellow spots } \\
\text { Reflex absent }\end{array}$ \\
\hline \multicolumn{5}{|l|}{ 1. Mendoza } \\
\hline San Martin & 93 & 45 & 28 & 19 \\
\hline Las Heras & 141 & 118 & 50 & 40 \\
\hline Lujan-Maipu & 58 & 28 & 20 & 6 \\
\hline Total & 292 & 181 & 98 & 65 \\
\hline \multicolumn{5}{|l|}{ 2. San Luiz } \\
\hline El Vulcan & 17 & 53 & - & - \\
\hline \multicolumn{5}{|l|}{ 3. Cordoba } \\
\hline Rio Cuarto, Rio Ajis & - & 27 & - & - \\
\hline Alta Gracia & - & 11 & - & - \\
\hline \multicolumn{5}{|l|}{ 4. Tucuman } \\
\hline San Miguel, Rio Sali & 7 & 393 & - & $1(?)$ \\
\hline \multicolumn{5}{|l|}{ 5. Buenos Aires } \\
\hline Avellaneda & - & 55 & - & - \\
\hline
\end{tabular}

1. The Mendoza population is polymorphic both for coloration and for the reflex, 25.2 per cent of the individuals having yellow spots, and 60.5 per cent showing the refiex. In the other populations spotted individuals are absent (except for one specimen with a very small yellow spot found at Tucuman). In the San Luiz population the hypnotic reflex is elicited in only 24.3 per cent of the individuals, and in Tucuman population in only 1.7 per cent of the individuals. The Cordoba and the Buenos Aires populations are monomorphic for both traits, i.e., unspotted and showing no reflex. The reflex and the yellow spots were also absent in the small sample of six specimens from Jorba (San Luiz), in several hundred of specimens inspected in the laboratory of the Institute of Biology M. Ferreira in Cordoba, and in 11 specimens from La Plata (Buenos Aires). The reflex and the yellow spots were both present in 42 specimens from San Carlos (120 km south of Mendoza) which is a very arid locality, and in five specimens from Potrerillo (foothills of the Andes facing Mendoza).

It appears, then, that the hypnotic reflex and the yellow spots occur in the populations of the arid regions of western
Argentine. Most interesting, a parallel variation is also observed in the related Chilean species, $B$. spinulosus, of which about 300 individuals have been studied. In the arid desert of Atacama (Vallenar) 22.9 per cent of the individuals exhibited the hypnotic reflex, and 66 per cent of the individuals from the arid valley of Curacavi, south of Valparaiso. In the Santiago population the frequency of the reflex declines to 17.2 per cent, in the little streams of the coast of Paposa (Antofagasta) to 5.2 per cent, and to zero in the mountain streams of the Puna de Atacama and in the Central Cordilleras facing Santiago.

A simple experiment was carried out with the toads from the Cordoba and from the Mendoza populations, to demonstrate the different resistance of these populations to severe environmental conditions. Samples were collected between November 13th and December 5th, 1956, in Cordoba (Rio Ajis) and at Mendoza (Parque San Martin). The toads were taken to Santiago de Chile, and on December 5 th placed in identical terraria, being cages with wire screens, and about $20 \mathrm{~cm}$. deep sand on the bottom. The terraria were not protected against evaporation, which is strong in the summer 
TABLE 2. Mean weight (in gr.) and mean water loss (in per cent) in samples of ten individuals from Mendoza and ten individuals from Cordoba populations

\begin{tabular}{|c|c|c|c|c|}
\hline & \multicolumn{2}{|c|}{ Mendoza } & \multicolumn{2}{|c|}{ Cordoba } \\
\hline & Mean & Range & Mean & Range \\
\hline \multicolumn{5}{|l|}{ Weight } \\
\hline Initial & $46.55 \pm 3.87$ & $30.6-66.9$ & $59.34 \pm 4.24$ & $41.3-90.1$ \\
\hline After 24 hours & $42.59 \pm 3.70$ & $27.3-62.3$ & $55.24 \pm 4.00$ & $38.4-83.4$ \\
\hline After 48 hours & $39.51 \pm 3.75$ & $24.3-59.8$ & $51.80 \pm 3.91$ & $35.6-79.3$ \\
\hline \multicolumn{5}{|l|}{ Water loss } \\
\hline 24 hours & $8.88 \pm 0.65$ & $6.6-13.2$ & $6.78 \pm 0.26$ & $5.4-7.6$ \\
\hline 48 hours & $16.26 \pm 1.33$ & $10.7-25.0$ & $12.83 \pm 0.31$ & $11.1-14.4$ \\
\hline
\end{tabular}

climate of Santiago. The food was very scarce. Now, the sample of 24 male specimens from Cordoba, all without yellow spots and without the hypnotic reflex, showed a 50 per cent mortality after three months of captivity (by March 5th, 1957), and 92 per cent mortality after five and a half months (by May 21st, 1957). By June 5th all the specimens were dead. The sample of 12 male specimens from Mendoza, all with the hypnotic reflex and two specimens with yellow spots, showed no mortality after three months, 16 per cent mortality after five and a half months, 25 per cent after nine months and the same after 11 months when the experiment was discontinued. The difference between the mortality rates in the Mendoza and the Cordoba samples is very significant.

To study the tolerance of the Mendoza and Cordoba toads to water loss, the animals were placed between March 11th and 16th, 1957, in glass chambers in which the humidity was reduced by $\mathrm{CaCl}_{2}$ (temperature $23^{\circ}-26^{\circ} \mathrm{C}$.). The results are shown in table 2 . It can be seen that the Mendoza toads lose water even more rapidly than do the Cordoba toads (the probability of the difference observed being due to chance lies between 0.01 and 0.02 for the 24-hours experiment and between 0.02 and 0.05 for the 48-hours experiment). It should be noted in this connection that the Mendoza toads are smaller than those from Cordoba, and that the per cent of the water loss is, as shown in figures 9 and 10, inversely correlated with the body size. Large specimens lose water more slowly than do smaller ones. The correlation coefficients $(r)$ computed for the data shown in nos. $2-5$ of plate 1 are as follows :

$\begin{array}{lrr} & \text { Mendoza } & \text { Cordoba } \\ 24 \text { hours } & -0.77 & +0.45 \\ 48 \text { hours } & -0.75 & -0.49\end{array}$

Examination of figures 1 and 2 also shows that the regression lines describing the relationships between body weight and per cent of water loss are steeper in

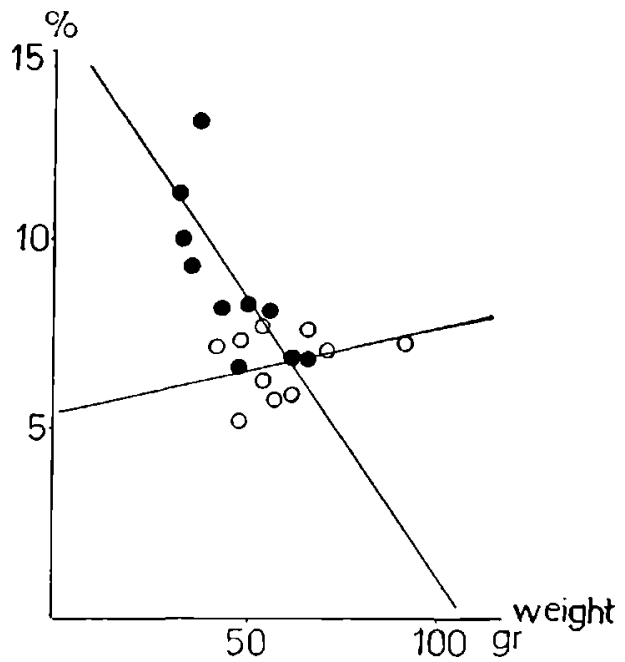

FIG. 1. Regression lines of the percent of water loss on the initial body weight ( $\mathrm{gr}$ ) in the Mendoza (filled circles) and Cordoba (empty circles) populations of Bufo arenarum, after a 24-hours-long exposure to desiccation. 


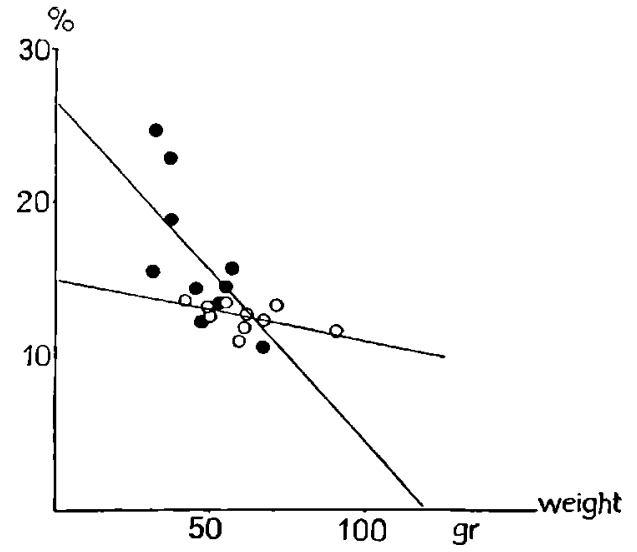

FIG. 2. Regression lines of the percent of water loss on the initial body weight (gr) in the Mendoza (filled circles) and Cordoba (empty circles) populations of Bufo arenarum, after a 48-hour-long exposure to desiccation.

the toads from Mendoza than in those from Cordoba. In fact, the former are strikingly similar to those obtained by Kirk and Hogben (1946) for Bufo bufo from England. The environmental conditions of Mendoza are, of course, completely unlike those in England.

\section{SumMary}

The populations of Bufo arenarum from Mendoza are polymorphic for a coloration character (presence and absence of yellow spots) and for a neurological character (presence or absence of the hypnotic reflex). The populations of Cordoba and of Buenos Aires are, as far as known, monomorphic, being unspotted and devoid of the hypnotic reflex. In Tucuman and San Luiz populations the coloration is monomorphic (unspotted), but both individuals with and without the hypnotic reflex are found.

It is surmised that the polymorphism is adaptive in the arid environments of western Argentine. Experimental tests do show that the toads from Mendoza survive longer under stringent conditions of dryness and starvation than do the toads from Cordoba. Nevertheless, direct measurements showed a greater rate of water loss and a higher metabolic rate in the Mendoza than in the Cordoba toads. Further observations are needed to unravel the physiological mechanisms which contribute to the higher adaptedness exhibited by the Mendoza populations under the conditions of the experiments.

\section{ACKNOWLEDGMENTS}

The author wishes to thank the C. I. Z. (Centro Investigaciones Zoologicas) of the University of Chile (Director, Prof. G. Mann) for the help received during the work. He is obligated also to Dr. J. Concha, the head of the Department of Neurophysiology of the C. I. Z., in whose laboratory the metabolic measurements have been made; to Dr. F. Vargas of the C. I. Z. for useful suggestions; to Mr. A. Escarate, head of the photographic laboratory of the C. I. Z., for excellent collaboration; to Dr. A. Pisano of the University of Cuyo, Mendoza, for his help in collecting the animals, and to Miss A. Garate, of the University of Cuyo, for reading the manuscript. Above all, the author wishes to express his gratitude to Prof. Th. Dobzhansky, of Columbia University, New York; for his suggestions and criticisms.

\section{Literature Cited}

CEI, J. M. 1956. Observaciones geneticas preliminares en poblaciones de anfibios argentinos. Biologica, 22: 45-49.

KIRK, R. L. And L. Hogmen. 1946. Studies on temperature regulation II. Amphibia and reptiles. Journal of Experimental Biology, 22: $213-220$. 